\title{
Gas leak and gastric insufflation during controlled ventilation: face mask versus laryngeal mask airway
}

Lily M. Ho-Tai MD FRCPC, J. Hugh Devitt MD MSC FRCPC, Alva G. Noel RRT, Michael P. O'Donnell RRT

Purpose: To compare two airway management techniques, face mask (FM) with oropharyngeal airway and laryngeal mask airway (LMA), with respect to the effectiveness of positive pressure ventilation and aiway maintenance.

Methods: After induction of anaesthesia, two airway management techniques (FM or LMA) and three peak pressures $\left(20,25\right.$ and $30 \mathrm{~cm} \mathrm{H}_{2} \mathrm{O}$ ) were randomly applied during controlled ventilation in 60 patients. Data collected included inspiratory and expiratory volumes and presence of gastro-oesophageal insufflation. Leak was calculated by subtracting the expiratory from the inspiratory volume, expressed as a fraction of the inspiratory volume.

Results: Expiratory volumes (mean \pm SD) at 20,25 and $30 \mathrm{~cm} \mathrm{H}_{2} \mathrm{O}$ for LMA ventilation were $893 \pm 260,986 \pm$ 276 and $1006 \pm 262$ respectively, and for FM ventilation $964 \pm 264,1100 \pm 268$ and $1116 \pm 261$. Leak fractions at 20,25 and $30 \mathrm{~cm} \mathrm{H}_{2} \mathrm{O}$ for $L M A$ ventilation were $0.21 \pm 0.15,0.24 \pm 0.18$ and $0.26 \pm 0.18$ respectively, and for $\mathrm{FM}$ ventilation $0.14 \pm 0.09,0.14 \pm 0.09$ and $0.12 \pm 0.08$. The frequency of gastro-oesophageal insufflation was $1.6 \%, 5 \%$ and $5 \%$ for the LMA and $5 \%, 15 \%$ and $26.6 \%$ for the FM for ventilation pressures of 20,25 and $30 \mathrm{~cm}$ $\mathrm{H}_{2} \mathrm{O}$ respectively which was greater with LMA use.

Conclusion: Ventilation was adequate in all patients using both techniques. Leak was pressure dependent and greater with LMA use. Most of the leak was vented to the atmosphere via the pharynx. Gastro-oesophageal insufflation was more frequent with ventilation using the face mask. LMA use with positive pressure ventilation would appear to be a better ainway management method than the face mask.

Objectif : Comparer deux techniques de maintien des voies aériennes, le masque facial (MF) avec canule oropharyngée et le masque lanyngé (ML) quant à l'efficacité de la ventilation à pression positive et du maintien des voies aériennes.

Méthodes : Après induction de l'anesthésie, on a utilisé de façon aléatoire chez 60 patients 2 méthodes de contrôle des voies aériennes (MF ou ML) et 3 pressions de pointe $\left(20,25\right.$ et $\left.30 \mathrm{~cm} \mathrm{H}_{2} \mathrm{O}\right)$ durant la ventilation contrôlée. Comme données on a colligé les volumes inspiratoires et expiratoires et la présence d'insufflation gastro-oesophagienne. La fuite a été calculée en soustrayant le volume expiré du volume inspiré et a été exprimée comme une fraction du volume inspiré.

Résultats : Pour la ventilation avec ML, les volumes expirés (moyenne \pm Écart type) mesurés à 20,25 et $30 \mathrm{~cm}$ $\mathrm{H}_{2} \mathrm{O}$ étaient respectivement de $893 \pm 260,986 \pm 276$ et $1006 \pm 262$, alors que pour la ventilation avec MF les volumes étaient respectivement de $964 \pm 264,1100 \pm 268$ et $1116 \pm 261$. La fraction de fuite à 20,25 et $30 \mathrm{~cm}$ $\mathrm{H}_{2} \mathrm{O}$ a été pour la ventilation avec $\mathrm{ML}$ respectivement de $0,21 \pm 0,15,0,24 \pm 0,18$ et $0,25 \pm 1,18$, alors qu'avec le MF elle atteignait $0,14 \pm 0,09,0,14 \pm 0,09$ et $0,12 \pm 0,08$. La fréquence de l'insufflation gastro-oesophagienne se situait respectivement à $1,6 \%, 5 \%$ et $5 \%$ pour le ML et à $5 \%, 15 \%$ et $26,6 \%$ pour le MF pour des pressions de ventilation de 20,25 et $30 \mathrm{~cm} \mathrm{H}_{2} \mathrm{O}$.

Conclusion : La ventilation a été adéquate chez tous les patients en utilisant l'une ou l'autre technique. La fuite était plus grande avec le ML, dépendait de la pression et était en grande partie évacuée dans l'atmosphère par le pharynx. Linsufflation gastro-oesophagienne était plus fréquente avec l'utilisation du MF. L'utilisation du ML lors de ventilation à pression positive semble une meilleure méthode de maintien des voies aériennes que l'utilisation du masque facial.

From the Department of Anaesthesia, Sunnybrook Health Science Centre, University of Toronto, 2075 Bayview Avenue, Toronto, Ontario M4N 3M5.

Presented at the annual meeting of The Canadian Anaesthetists' Society, Montréal 1996.

Address correspondence to: Dr. J. Hugh Devitt; Phone: 416-480-4864; Fax: 416-480-6039; E-Mail: j.hugh_devitt@mail.magic.ca Accepted for publication December 21, 1997. 
A $\mathrm{N}$ early description of the LMA recommended this device for patients who required general anaesthesia with spontaneous ventilation where tracheal intubation was not indicated. ${ }^{1}$ The use of this device then broadened to include instances where positive pressure ventilation was mandatory, such as failed intubation or inadequate reversal of neuromuscular blockade. ${ }^{2-4}$ Some jurisdictions have reported positive pressure ventilation with $44 \%$ of their LMA insertions. ${ }^{5,6}$ It has been recommended that positive pressure ventilation can be safely used, provided the risk of aspiration is low, the patient is deeply anaesthetised and pulmonary compliance and airway resistance are normal. 7,8

The LMA offers several advantages with respect to standard anaesthesia mask and airway techniques. These include: decreased risk of eye or nerve injuries, decreased operating room pollution, freeing the anaesthetist's hands for other aspects of patient care, minimal cardiovascular responses and ease of placement. ${ }^{9,10}$ Disadvantages of the LMA with respect to standard mask techniques include: a failure of placement rate of up to $5 \%$ which necessitates other forms of airway management, gastric insufflation, and regurgitation or vomiting. ${ }^{9,10} \mathrm{~A}$ more recent report describes a failure of placement rate of $0.19 \%$ and one pulmonary aspiration in 11,910 patients. While this group of anaesthetists was particularly experienced with the use of the LMA, these results compare very favourably with other airway management techniques. ${ }^{6,11}$

The LMA is placed in a blind manner into the pharynx so that the distal end of the cuff just enters the proximal oesophagus. The cuff is then inflated sealing against the upper oesophageal sphincter, aryepiglottic folds and distal epiglottis. ${ }^{12}$ A clear view of the oesophagus has been documented by fibre-optic bronchoscopy in 6-9\% of patients. ${ }^{13,14}$ The position of the distal end of the LMA could theoretically render the upper oesophageal sphincter incompetent and lead to gastro-oesophageal insufflation during positive pressure ventilation. The incidence of gastro-oesophageal insufflation, assessed qualitatively, is airway pressure dependent. ${ }^{15}$ There are anecdotal reports describing gastric dilatation and regurgitation of gastric contents when positive pressure ventilation has been used with the LMA. ${ }^{16,17}$

The LMA has been recommended as a rescue airway manoeuvre in several instances where positive pressure ventilation may be necessary. ${ }^{9}, 10$ We wished to compare the LMA with the anaesthesia face mask with respect to the amount of ventilation, leak, and gastro-oesophageal insufflation during positive pressure in order to determine if either airway method had advantages during positive pressure ventilation. We hypothesised that use of the LMA would lead to increased gastro-oesophageal insufflation of gas during positive pressure ventilation.

\section{TABLE Exclusion Criteria}

1. Severe acure or chronic lung disease

2. Upper airway abnormalities that may make intubation difficult and preclude the use of neuromuscular blocking agents

3. Hiatus hernia with gastro-oesophageal reflux or other oesophageal or gastric abnormalities that require a rapid sequence induction.

4. Food or drink within six hours of surgery.

5. Ischaemic or congenital heart disease.

6. Pregnancy

7. Facial hair or facial anatomical abnormality which would preclude an adequate mask seal.

\section{Materials and methods}

The study had the approval of the institutional research ethics committee. Patients of American Society of Anesthesiologists' (ASA) physical status 1 or 2 undergoing elective surgical procedures which ordinarily involved tracheal intubation were studied. Exclusion criteria are outlined in the table above. Informed consent was obtained from each patient the night before surgery for inpatients or on the morning of surgery for same day of admission patients and outpatients.

In the operating room, an intravenous infusion was established and standard monitors including a peripheral nerve stimulator were attached. The patient's anaesthetist was not one of the investigators. After baseline measurements, anaesthesia was induced with the choice of induction agent being left to the discretion of the patient's anaesthetist. Neuromuscular blockade was achieved with a non-depolarising muscle relaxant $\left(0.1 \mathrm{mg} \cdot \mathrm{kg}^{-1}\right.$ vecuronium). After induction of anaesthesia, ventilation by face mask with oxygen $100 \%$ (oxygen flow $6 \mathrm{l} \cdot \mathrm{min}^{-1}$ ) was performed until the onset of neuromuscular blockade. Neuromuscular blockade was assessed with train-of-four stimulation. The study proceeded when a single response to the train-of-four remained. Neuromuscular blockade was used in all patients to eliminate any variation due to induction technique.

Positive pressure ventilation with two airway management techniques was performed on each patient. The order of the airway technique was assigned from a block randomisation schedule. The two airway management techniques were:

1. A standard anatomical anaesthesia face mask (size \#4 or \#5, depending on sex and size of patient) with a Guedel oropharyngeal airway. Airway management, insertion of the oropharyngeal airway and placement of the anaesthesia mask were performed by a single experienced investigator. A onehanded mask technique was used. 
2. An LMA, Size \#3 or \#4, was used depending on the size and sex of the patient. The LMA cuff was inflated with $30 \mathrm{ml}$ air and the position of the LMA and airway patency was checked by gentle manual ventilation of the lungs assessing the resistance, compliance and leak of the airway. The LMA was inserted by the same investigator and taped to the patient's face for the trial.

Once an acceptable airway had been confirmed by the clinician, no further adjustments were made to the airway during the study. After confirmation of a patent airway with each technique, the face mask or the LMA was connected directly to a Siemens Servo-900C ventilator. Ventilation was commenced with a square wave form in the pressure control mode. The tidal volume was dependent upon ventilation pressure, resistance of the patient's airways and compliance of the patient's lungs. Lungs were ventilated with oxygen $100 \%$ at a rate of $10 \mathrm{bpm}$. An inspiratory/expiratory ratio of $1: 4$ was used to allow for adequate emptying of the lungs during the expiratory phase. Low compliance, wide bore tubing was used, and all connections were checked for leaks.

Lung ventilation occurred at three different pressure settings $\left(20,25\right.$ and $\left.30 \mathrm{~cm} \mathrm{H}_{2} \mathrm{O}\right)$ for both airway management techniques. Ventilator pressures were assigned to each airway technique by a randomised block schedule so as to eliminate any variables due to the time of ventilation. The investigator performing the airway management techniques was blinded to the pressure settings during each observation. Measurements were taken over 10 breaths at each pressure setting.

Flow transducers were placed in the inspiratory and expiratory limbs of the breathing circuit and the output integrated electronically to determine the inspiratory and expiratory volumes. The flow signal, volumes and the pressure wave form were recorded on a computer disc via an analog to digital converter. Gastrooesophageal insufflation was qualitatively assessed by a single investigator blinded to the ventilating pressures listening over the stomach with a stethoscope during ventilation. During each airway management technique data collected included presence of gastro-oesophageal insufflation, airway pressure, inspiratory and expiratory volumes for each of the three ventilation pressures. Once data collecrion was complete for the first airway management technique, the corresponding airway equipment was removed and the second airway management method was instituted. The measurements were repeated for the second airway management technique.

After completion of data collection, the inspiratory and expiratory flow transducers were calibrated with a rolling seal spirometer while ventilating a test lung. The inspiratory and expiratory volumes were corrected against the calibration volumes. Leak was determined by subtracting the expiratory volume from the inspiratory volume. The leak was expressed as a fraction of the inspiratory volume. Data analysis for volumes and calculation of leak were done by an investigator unaware of the ventilation pressures and the airway management techniques.

\section{Statistical analysis}

The study design involved two within subject fixed factors: airway management technique with two levels (FM or LMA) and ventilation pressure with three levels $\left(20,25\right.$ and $\left.30 \mathrm{~cm} \mathrm{H}_{2} \mathrm{O}\right)$. The balancing of the order of both technique and pressure was accomplished for each patient according to a computer generated randomisation schedule. Three dependent measures were taken at each level: 1) airway leak expressed as a fraction of inspired volume, 2) expiratory volume and 3) gastro-oesophageal insufflation coded as a dichotomous variable. The appropriate statistical method to analyse each of the two continuous dependent measures was a two way repeated measures analysis of variance with subsequent selected contrasts. The dichotomous variable of insufflation was analysed using a weighted least squares methodology incorporating multiple repeated measures factors. All data are expressed as a mean \pm standard deviation. A $P<0.05$ was considered statistically significant.

\section{Results}

Sixty patients were studied over 11 months. There was a male-to-female ratio of 29:31. Subjects had an age (mean \pm SD) of $44.0 \pm 17.1$ yr. (range 19-82) and a weight (mean $\pm S D) 71.1 \pm 13.0 \mathrm{~kg}$ (range 41-97). Insertion of the LMA was accomplished on the first attempt in all but three cases. In those three cases the LMA was inserted successfully on the second attempt.

Expiratory volumes ranged between 964 to $1116 \mathrm{ml}$ and 893 to $1006 \mathrm{ml}$ for FM and LMA ventilation respectively. Mean expiratory volumes for both the FM and LMA are presented in Figure 1. The interaction between the two airway techniques (FM and LMA) and the three ventilation pressures was not significant $\left(F_{2,118}=1.19, P=N S\right.$. $)$. This means that the changes in expiratory volume trended in the same direction and proportion for both airway management techniques over the three ventilation pressures. Expiratory volume was lower with the use of the LMA $\left(\mathrm{F}_{1,59}=6.84\right.$, $P<0.02$ ) but increased with ventilation pressure for both FM and LMA $\left(\mathrm{F}_{2,118}=46.30, P<0.0001\right)$.

Leak, expressed as a fraction of the inspired volume increased with the use of the LMA from 0.21 at $20 \mathrm{~cm}$ $\mathrm{H}_{2} \mathrm{O}$ to 0.26 at $30 \mathrm{~cm} \mathrm{H} \mathrm{H}_{2} \mathrm{O}$ ventilation pressure 
(Figure 2). An audible pharyngeal leak was heard in most instances. The overall interaction between the two airway management techniques and the three ventilation pressures was statistically significant $\left(\mathrm{F}_{2,118}=4.66\right.$, $P<0.02$ ) demonstrating a divergence pattern of leak fraction over increasing ventilation pressure. Although the leak fraction associated with LMA use increased with ventilation pressure, leak remained relatively constant with FM use for all ventilation pressures. The change in leak fraction between ventilation pressures from 25 to $30 \mathrm{~cm} \mathrm{H} \mathrm{H}_{2} \mathrm{O}$ for the two airway management methods was statistically significant $\left(\mathrm{F}_{1,59}=4.16, P<0.05\right)$.

There was a significant airway management technique by ventilation pressure interaction in the frequency of gastro-oesophageal insufflation $\left(\chi_{2}^{2}=9.34, P<0.01\right)$ in that there was a divergence pattern with increasing gastro-oesophageal insufflation frequency at higher ventilation pressure with the use of FM ventilation. The change in the difference of gastro-oesophageal insufflation

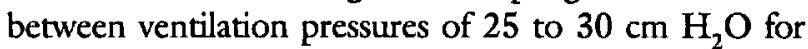
the two methods of airway management was statistically significant $\left(\chi_{1}^{2}=6.38, P<0.02\right)$ (Figure 3 ).

\section{Discussion}

Comparable ventilation of the lungs was achieved in all subjects with both airway techniques (LMA and FM) as assessed by measurement of expiratory volume. Leak was directly proportional to the ventilation pressure for the LMA and constant for the FM, in the range of ventilation pressures studied. The data are comparable to that previously reported. ${ }^{15,18}$ Expiratory volumes for both airway management techniques met American Heart Association resuscitation standards. ${ }^{19}$ The lower expired

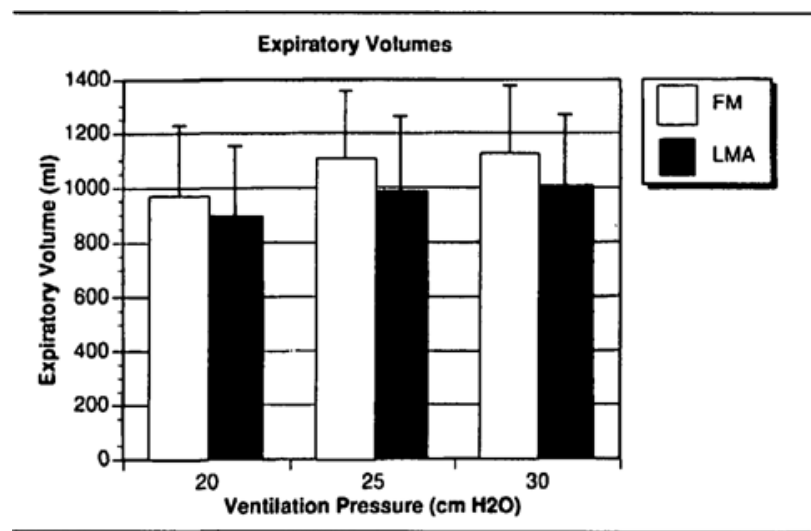

FIGURE 1 Expiratory volume (mean $\pm S D$ ) for ventilation with the face mask (FM) or laryngeal mask airway (LMA) at different ventilation pressures. The interaction between airway device and ventilation pressure is not significant. Expiratory volume was lower with the use of the LMA $(P<0.02)$ but increased with ventilation pressure for both FM and LMA $(P<0.0001)$. volume in the LMA group was not clinically significant and likely due to increased leak of air into the pharynx and not into the stomach. The frequency of gastrooesophageal insufflation increased as higher inflation pressures were used. However, ventilation with the LMA resulted in a lower incidence of gastro-oesophageal insufflation than ventilation with a face mask.

With LMA use, the greater volume of gas leak in combination with the lesser frequency of gastrooesophageal insufflation would indicate that most of the leak was vented to the atmosphere via the pharynx and not into the stomach. Several other studies have demonstrated the phenomenon of a lower frequency

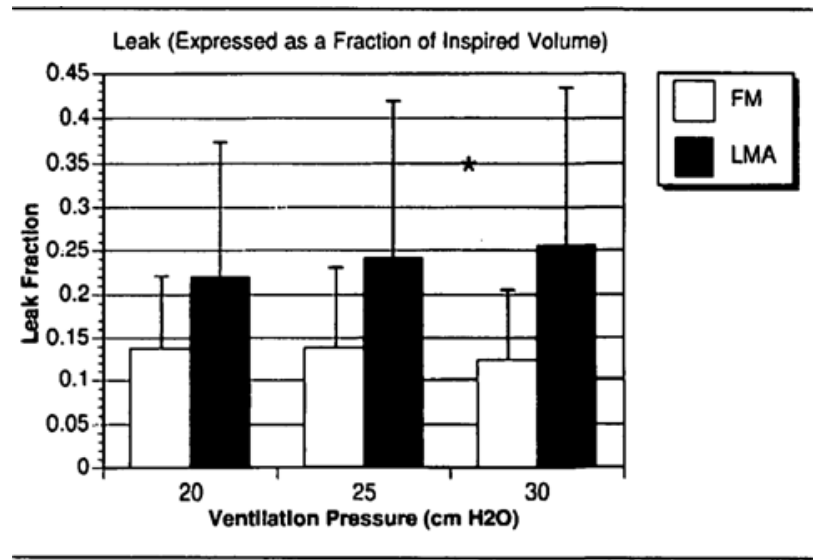

FIGURE 2 Leak (mean $\pm S D$ ), expressed as a fraction of inspired volume, with the FM and LMA at different ventilation pressures. There is a significant interaction between airway management method and ventilation pressure $(P<0.02)$ with a diverging pattern of leak fraction with increasing ventilation pressure. The difference in leak fraction between ventilation pressures 25 and $30 \mathrm{~cm} \mathrm{H}_{2} \mathrm{O}\left({ }^{*} P<0.05\right)$ was statistically significant.

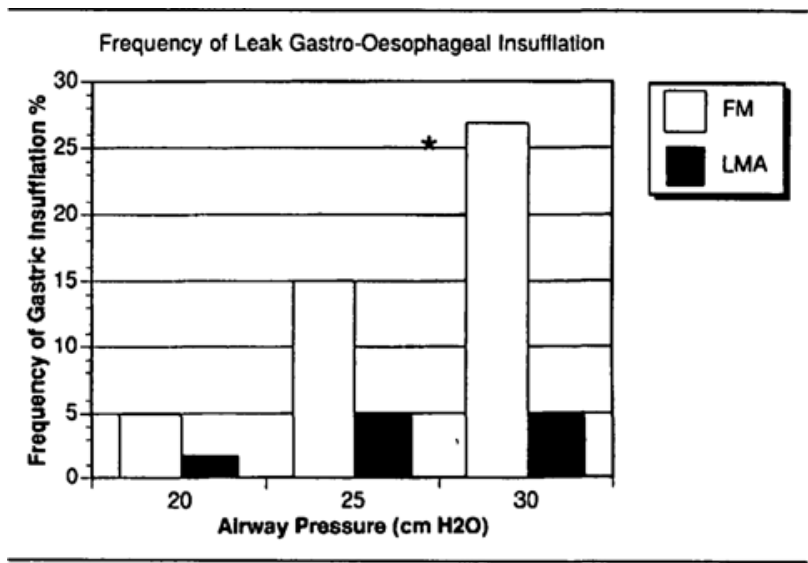

FIGURE 3 The frequency of gastro-oesophageal insufflation at different ventilation pressures. There was a significant rise in the frequency of gastro-oesophageal insufflation from 25 and $30 \mathrm{~cm}$ $\mathrm{H}_{2} \mathrm{O}$ ventilation pressure $\left({ }^{*} P<0.02\right)$. 
of gastro-oesophageal insufflation with greater leak fractions. ${ }^{18,20}$ We had hypothesised that there would be an increased incidence of gastro-oesophageal insufflation with the LMA because the location of this device in the pharynx could potentially defeat the function of the upper esophageal sphincter. The upper esophageal sphincter may not be important in preventing gastro-oesophageal insufflation. ${ }^{21}$

We can offer two possible explanations for our findings. First, the face mask technique requires the anaesthetist to seal the mask against the skin of the face. If this seal is defective resulting in a noticeable leak the anaesthetist would automatically compensate for the leak by trying to re-establish a seal of the mask against the face. If this manoeuvre were successful the amount of gas vented to the atmosphere would be less and the pharynx and upper oesophageal sphincter would be subject to a greater pressure and gas flow which could potentially lead to an increased frequency of gastrooesophageal insufflation. On the other hand, the cuff pressure and volume of the laryngeal mask was not altered during the study period. Our study likely reflects reality for face mask ventilation in that there is a natural tendency for the anaesthetist to increase the grip on the face mask in order to achieve a better seal in the presence of an obvious leak. It is possible, although not investigated in this study, that attempts to seal an LMA leak by placing more air in the cuff would result in an increased frequency of gastro-oesophageal insufflation and a smaller leak fraction. Second, two studies have noted that patients with gastro-oesophageal insufflation tended to have a lower overall leak fraction than those without gastro-oesophageal insufflation. ${ }^{18,20}$ Weiler et al. have postulated that when gas is prevented from venting from the pharynx to the atmosphere it will more likely find its way to the stomach. ${ }^{20}$

Our study has several flaws. It was conducted in highly artificial and ideal surroundings utilising fully relaxed, healthy subjects. Many conditions were excluded that could alter airway resistance or pulmonary compliance and therefore potentially increase the amount of leak or gastro-oesophageal insufflation. Pressure controlled ventilation was used to ensure that ventilation pressures would be kept constant. This form of ventilation would maximise any leak as gas flow would continue during inspiration until the pressure limit was met.

The weakest part of our study is the qualitative method used to determine gastro-oesophageal insufflation. Lawes and coworkers have suggested that it is possible to detect as little as $5 \mathrm{ml}$ air entering the stomach with a stethoscope place over the epigastrium. ${ }^{22}$ However, we were unable to quantitate the amount of air entering the stomach with our technique. There were no episodes of regurgitation or pulmonary aspiration in our patients during the study or the subsequent anaesthesia and surgery. Our study period was short and we speculate that patients may have had a large volume of gas insufflated into their stomach if gastro-oesophageal insufflation continued to be present over a prolonged period of time. Weiler et al documented gastrooesophageal insufflation during positive pressure ventilation with a LMA using an epigastric microphone. This technique is reported to detect as little as $2 \mathrm{ml}$ air entering the stomach. The higher incidence of gastrooesophageal insufflation documented by this group may be due to the different measuring technique. ${ }^{20}$

The frequency of gastro-oesophageal insufflation with the LMA appeared to be smaller at higher ventilation pressures in our study than that reported in a previous study of similar design. ${ }^{15}$ In this study, as well as the previous one, the LMA was inserted by an experienced anaesthetist. There were several differences in LMA insertion technique. In this study the cuff was inflated with $30 \mathrm{ml}$ of air compared to $20 \mathrm{ml}$ in the previous study. The choice of LMA in this study was based on patient size rather than on sex. Use of a larger LMA or larger cuff volumes may have reduced the leak associated with the LMA but these manipulations may increase the frequency of gastro-oesophageal insufflation..$^{20}$ Finally, the order of airway management techniques was randomised. In the previous study the order of airway technique was fixed in that measurements with the LMA always preceded measurements with the tracheal tube. ${ }^{15}$

We conclude that ventilation using the LMA is as effective and comparable to ventilation using the FM with respect to leak fraction and expiratory volume. However, gastro-oesophageal insufflation was more frequent with ventilation using the face mask. This would suggest that the LMA is a better than FM as a method of airway management during positive pressure ventilation.

\section{Acknowledgment}

The authors would like to gratefully acknowledge the statistical guidance provided by Mr. Marko Katic. We would also like to thank David Leung and. Nazeer Ahmad for assistance with calibration of our equipment.

\section{References}

1 Brodrick PM, Webster NR, Nunn JF. The laryngeal mask airway. A study of 100 patients during spontaneous breathing. Anaesthesia 1989; 44: 238-41.

2 Kumar CM. Laryngeal mask airway for inadequate reversal (Letter). Anaesthesia 1990; 45: 792.

3 Brain AIJ. Three cases of difficult intubation overcome by the laryngeal mask airway. Anaesthesia 1985; 40 : 353-5. 
4 Practice guidelines for management of the difficult airway. A report by the American Society of Anesthesiologists task force on management of the difficult airway. Anesthesiology 1993; 78: 597-602.

5 Maltby JR, Loken RG, Watson NC. The laryngeal mask airway: clinical appraisal in $\mathbf{2 5 0}$ patients. Can J Anaesth 1990; 37: 509-13.

6 Verghese $C$, Brimacombe JR. Survey of laryngeal mask airway usage in 11,910 patients: safety and efficacy for conventional and nonconventional usage. Anesth Analg 1996; 82: 129-33.

7 Fisher JA, Ananthanarayan $C$, Edelist $G$. Role of laryngeal mask in airway management (Editorial). Can J Anaesth 1992; 39: 1-3.

8 Benumof $J L$. Laryngeal mask airway. Indications and contraindications (Editorial). Anesthesiology 1992; 77 : 843-6.

9 Pennant JH, White $P F$. The laryngeal mask airway. Its uses in anesthesiology. Anesthesiology 1993; 79: 144-63.

10 Asai $T$, Morris $S$. The laryngeal mask airway: Its features, effects and role. Can J Anaesth 1994; 41: 930-60.

11 Warner MA, Warner ME, Weber JG. Clinical significance of pulmonary aspiration during the perioperative period. Anesthesiology 1993; 78: 56-62.

12 Brain $A I J$. The laryngeal mask - a new concept in airway management. Br J Anaesth $1983 ; 55$ : 801-5.

13 Payne J. The use of the fibreoptic laryngoscope to confirm the position of the laryngeal mask (Letter). Anaesthesia 1989; 49: 865.

14 John RE, Hill S, Hughes TJ. Airway protection by the laryngeal mask. A barrier to dye placed in the pharynx. Anaesthesia $1991 ; 46: 366-7$.

15 Devitt JH, Wenstone $R$, Noel $A G, O^{\prime}$ Donnell MP. The laryngeal mask airway and positive-pressure ventilation. Anesthesiology 1994; 80: 550-5.

16 Griffin RM, Hatcher IS. Aspiration pneumonia and the laryngeal mask airway. Anaesthesia 1990; 45: 1039-40.

17 Nanji GM, Maltby JR. Vomiting and aspiration pneumonitis with the laryngeal mask airway. Can J Anaesth 1992; 39: 69-70.

18 Devitt JH, Brooks DA, Oakley PA, Webster PM. Mask lung ventilation by ambulance personnel: a performance assessment. Can J Anaesth 1994; 41: 111-5.

19 Anonymous. Guidelines for cardiopulmonary resuscitation and emergency cardiac care. Emergency Cardiac Care Committee and Sub Committees, American Heart Association. Part III: Adult advanced cardiac life support. JAMA 1992; 268: 2199-241.

20 Weiler N, Latorre $F$, Eberle B, Goedecke $R$, Heinrichs $W$. Respiratory mechanics, gastric insufflation pressure, and air leakage of the laryngeal mask airway. Anesth Analg 1997; 84: 1025-8.
21 Vanner RG, O'Dwyer JP, Pryle BJ, Reynolds $F$. Upper oesophageal sphincter pressure and the effect $04 \mathrm{f}$ cricoid pressure. Anaesthesia 1992; 47: 95-100.

22 Lawes EG, Campbell I Mercer D. Inflation pressure, gastric insufflation and rapid sequence induction. Br J Anaesth 1987; 59: 315-8. 